\title{
Mechanism of active silica nanofluids based on interface-regulated effect during spontaneous imbibition
}

\author{
Xu-Guang Song ${ }^{1,2} \cdot$ Ming-Wei Zhao ${ }^{1,2} \cdot$ Cai-Li Dai ${ }^{1,2} \cdot$ Xin-Ke Wang $^{1,2} \cdot$ Wen-Jiao Lv $^{1,2}$
}

Received: 1 September 2020 / Accepted: 12 November 2020 / Published online: 4 January 2021

(c) The Author(s) 2020

\begin{abstract}
The ultra-low permeability reservoir is regarded as an important energy source for oil and gas resource development and is attracting more and more attention. In this work, the active silica nanofluids were prepared by modified active silica nanoparticles and surfactant BSSB-12. The dispersion stability tests showed that the hydraulic radius of nanofluids was $58.59 \mathrm{~nm}$ and the zeta potential was $-48.39 \mathrm{mV}$. The active nanofluids can simultaneously regulate liquid-liquid interface and solid-liquid interface. The nanofluids can reduce the oil/water interfacial tension (IFT) from 23.5 to $6.7 \mathrm{mN} / \mathrm{m}$, and the oil/water/solid contact angle was altered from $42^{\circ}$ to $145^{\circ}$. The spontaneous imbibition tests showed that the oil recovery of $0.1 \mathrm{wt} \%$ active nanofluids was $20.5 \%$ and $8.5 \%$ higher than that of $3 \mathrm{wt} \% \mathrm{NaCl}$ solution and $0.1 \mathrm{wt} \% \mathrm{BSSB}-12$ solution. Finally, the effects of nanofluids on dynamic contact angle, dynamic interfacial tension and moduli were studied from the adsorption behavior of nanofluids at solid-liquid and liquid-liquid interface. The oil detaching and transporting are completed by synergistic effect of wettability alteration and interfacial tension reduction. The findings of this study can help in better understanding of active nanofluids for EOR in ultra-low permeability reservoirs.
\end{abstract}

Keywords Active nanofluids $\cdot$ Regulate interface $\cdot$ Ultra-low permeability $\cdot$ Spontaneous imbibition

\section{Introduction}

With the technology development of oil and gas exploration, unconventional oil and gas resources have become a new global energy supply. The ultra-low permeability reservoirs are important parts of unconventional oil and gas resources; there are great challenges in exploitation and utilization. Compared with conventional reservoirs, ultra-low permeability reservoirs have the characteristics of low porosity, low permeability, and poor connectivity (Zhao et al. 2014; Qu

Edited by Yan-Hua Sun

Ming-Wei Zhao

zhaomingwei@upc.edu.cn

$\triangle$ Cai-Li Dai

daic1@upc.edu.cn

1 Key Laboratory of Unconventional Oil and Gas Development, Ministry of Education, School of Petroleum Engineering, China University of Petroleum (East China), Qingdao 266580, Shandong, China

2 Shandong Key Laboratory of Oilfield Chemistry, School of Petroleum Engineering, China University of Petroleum (East China), Qingdao 266580, China et al. 2016; Qiao et al. 2017; Peng et al. 2018; Zhang et al. 2019; Wang et al. 2019). It has become a decisive problem restricting the development of ultra-low permeability oil and gas resources. The key to developing ultra-low permeability oil and gas resources is increasing the utilization of matrix reserves.

Spontaneous imbibition is a process in which the wetting phase in porous media displaces the non-wetting phase under the action of capillary force (Jamaloei et al. 2010; Meng et al. 2015; Foley et al. 2017; Jabbari et al. 2019). Spontaneous imbibition is an extremely important mechanism for EOR in ultra-low permeability reservoirs. Surfactants are commonly used as spontaneous imbibition agents, which can enhance oil recovery primarily through reducing interfacial tension (IFT) and altering wettability. Many studies of spontaneous imbibition of surfactants have been reported. Standnes (2004) studied the oil recovery rates of spontaneous imbibition for cationic surfactants $\mathrm{C}_{n} \mathrm{TAB}$ by estimation of capillary diffusivity coefficients in oil-wet carbonates. Xie et al. (2005) pointed out that spontaneous imbibition recovery rate was faster in nonionic surfactant solutions than in cationic surfactant solutions owing to the lower interfacial tension. Saputra et al. (2016) provided the field 
data analysis and the numerical field-scale model evidences that the addition of surfactant into an oil/water/rock system enhanced spontaneous imbibition oil recovery by reducing the IFT. Mirchi et al. (2017) measured the equilibrium IFT and found the surfactant solution playing an important role in local trapping of oil phase during spontaneous imbibition. Ali et al. (2020) proved ferro-nanoparticles accounted for the effectiveness in reducing interfacial tension because of higher silicate sorption capacity.

In recent years, $\mathrm{SiO}_{2}, \mathrm{TiO}_{2}$, and other nanomaterials have been used more and more in oilfields (Dai et al. 2015a, b; Ehtesabi et al. 2014, 2015; Li et al. 2017a, b; Olayiwola et al. 2019a, b, 2020a, b; Wang et al. 2018; Xu et al. 2020; Zhao et al. 2020; Zhou et al. 2019). Due to nanoscale size and unique thermodynamic properties, nanofluids show great potential in spontaneous imbibition EOR processes. Nanoparticles can enter porous media and effectively adsorb at the solid-liquid interface to alter wettability, thus improving the effect of spontaneous imbibition. There have been many investigations into the impact of nanofluids on wettability. Li et al. (Li et al. 2017a) presented that the silica-based nanofluid is a promising method to enhance oil recovery in water-wet sandstone reservoirs by altering the wettability to neutral-wet. Erfani et al. (2017) concluded that the water-based nanofluid is better used in high permeability sandstone rocks. Nowrouzi et al. (2019) investigated the effects of concentration and size of $\mathrm{TiO}_{2}$ nanoparticles on wettability alteration and oil production during spontaneous imbibition. Wu et al. (2020) studied silica-based amphiphilic Janus nanofluid with improved interfacial properties and stable adsorption for EOR. Farad et al. (2020) found that hydroxyl-functionalized silica-based nanofluids altered the wettability from intermediate-wet to stronger water-wet as the concentration of nanoparticles increased. Eltoum et al. (2020) summarized and analyzed different kinds of nanoparticles on wettability alteration.

Spontaneous imbibition is an important mechanism for EOR in low permeability reservoirs. The nanofluids of pure nanoparticles have less effect of reducing IFT and are unstable for long-term effectiveness, while for surfactant solutions, the effectiveness of spontaneous imbibition is limited due to too much loss of surfactants. As shown in Fig. 1, when combining nanoparticles and surfactants together, the interfacial tension can be reduced and wettability can be altered. This type of nanofluids (also called active nanofluids) has higher oil displacement potential than pure surfactant solutions or pure nanofluids. Nwidee et al. (2017) studied that all these different surfactant-nanoparticle nanofluids $\left(\mathrm{ZrO}_{2} /\right.$ $\mathrm{C}_{16} \mathrm{TAB}, \mathrm{ZrO}_{2} / \mathrm{TX}-100, \mathrm{NiO} / \mathrm{C}_{16} \mathrm{TAB}$ and NiO/TX-100) can alter the wettability of oil-wet limestone during spontaneous imbibition. Zhao et al. (2018) proved that the spontaneous imbibition oil recovery of silica nanofluids was higher than that of TX-100 solution in the same concentration. Zhong et al. (2019) developed a kind of nonionic surfactant by integrating with hydrophilic silica nanoparticles for EOR.

Our group has also done a lot of research on the spontaneous imbibition of nanofluids. Most of previous studies focused on the low permeability $(1-10 \mathrm{mD})$ reservoirs, and the study of ultra-low permeability $(0.1-1 \mathrm{mD})$ has not been further carried out. In this work, interface-regulated nanofluids were prepared and showed excellent ability to enhance spontaneous imbibition recovery of ultra-low permeability cores. At present, the research on active nanofluids mainly focused on the improvement of some specific properties of pure surfactants by adding nanoparticles, and the mechanism of spontaneous imbibition was mainly explained by the synergistic effect of nanoparticles and surfactants on oil droplet detachment. However, the effects of nanoparticles and surfactants on the adsorption behavior at solid-liquid and liquid-liquid interfaces are not clear. In addition, after oil droplets are detached from the formation surface, the migration of oil droplets by nanofluids in pore throats has also not been discussed in depth.

In this work, the active nanofluids were prepared by nonionic surfactant BSSB-12 and modified silica nanoparticles. The nanofluids can simultaneously regulate oil/water and oil/solid interface to reduce interfacial tension and alter wettability. It can improve the oil displacement in ultra-low permeability reservoirs through synergistic effect of surfactant and nanosilica. The nanofluids prepared in this study have some limitations. The average particle size of nanofluids is among 50-60 $\mathrm{nm}$. It may be not suitable for tight and shale reservoirs with much lower permeability. When the temperature is more than $90{ }^{\circ} \mathrm{C}$ and the salinity exceeds $100,000 \mathrm{mg} / \mathrm{L}$, the stability of nanofluids will become worse. The active silica nanofluids are also not suitable for reservoir brine with high divalent ion contents, such as $\mathrm{Ca}^{2+}$ and $\mathrm{Mg}^{2+}$.

\section{Experimental}

\subsection{Materials and apparatus}

Sodium hydroxide $(\mathrm{NaOH})$, hydrochloric acid $(\mathrm{HCl})$, ethyl alcohol $\left(\mathrm{C}_{2} \mathrm{H}_{5} \mathrm{OH}\right)$, and $\mathrm{N}, \mathrm{N}$-dimethylformamide (DMF) were provided by Xilong Chemical Co., Ltd., China. Silica nanoparticles, vinyltriethoxysilane (VTES), 2-mercaptobenzimidazole, and 2,2-dimethoxy-2-phenylacetophenone (DMPA) were purchased from Aladdin Reagent Co., Ltd., China. Surfactant BSSB-12 (dodecyl sulfobetain) was from Shanghai Chuxing Chemical Co., Ltd., China. The simulated oil used in this study was a mixture of dehydrated crude oil obtained from Xinjiang Oilfield, and kerosene with a volume ratio of 1:17. $3 \mathrm{wt} \% \mathrm{NaCl}$ solution was used as reservoir brine with a density of $1.02 \mathrm{~g} /$ 


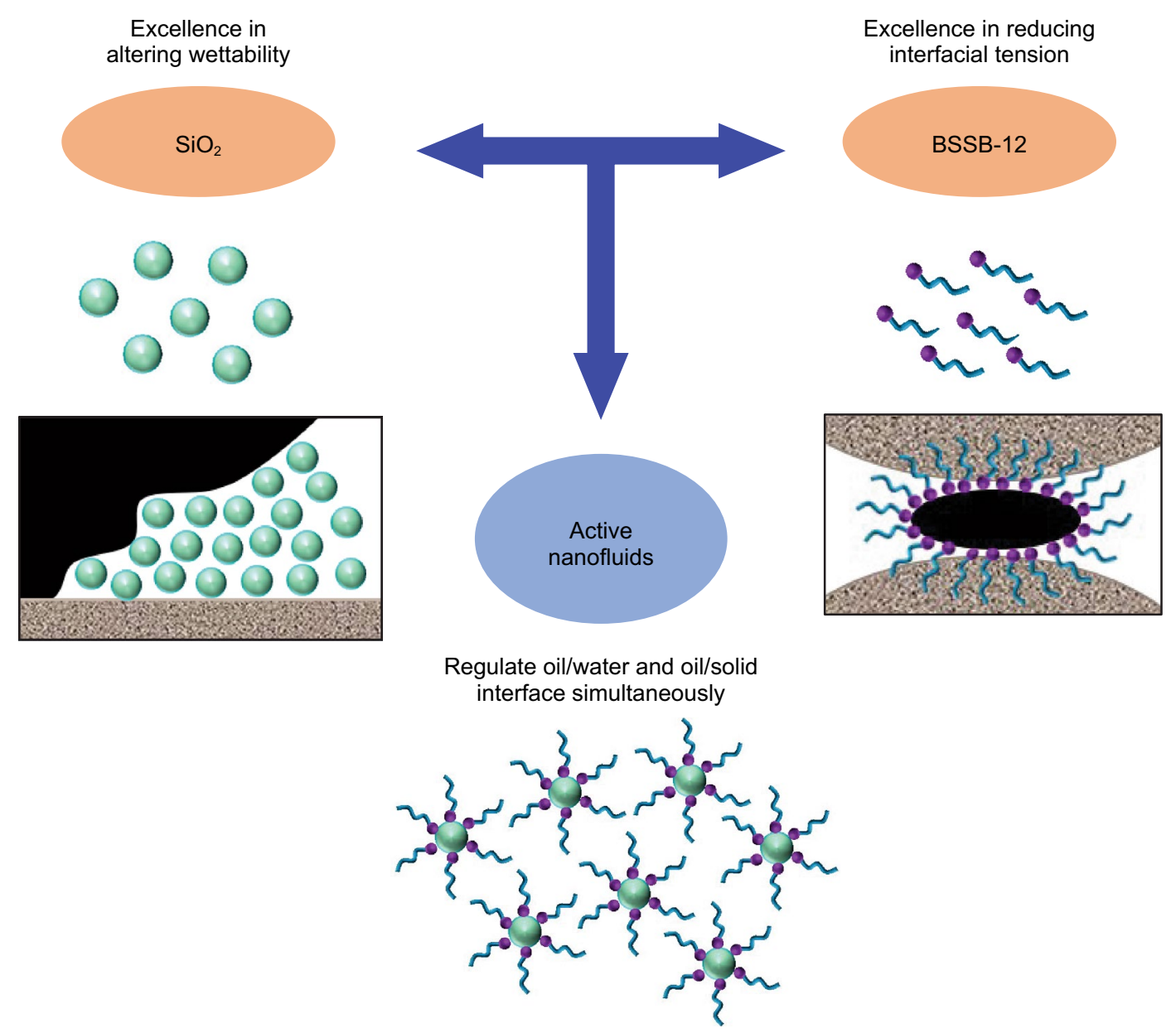

Fig. 1 The effect of interface-regulated active silica nanofluids

$\mathrm{cm}^{3}$ and a dynamic viscosity of $0.91 \mathrm{mPa}$ s at $25^{\circ} \mathrm{C}$. The ultra-low permeability sandstone cores with gas permeability of about $0.2 \mathrm{mD}$ and porosity of about $15 \%$ were purchased from Haian Oil Scientific Research Apparatus Co., Ltd., China.

The morphology of modified silica nanoparticles was characterized with a JEM-2100 transmission electron microscope (TEM) (Japan Electronics Co., Ltd.). The particle size and zeta potential were measured by a NanoBrook Omni laser particle size analyzer (Brookhaven Instruments Co., Ltd). To determine the interfacial activity, the interfacial tensions between oil and active nanofluids were measured at $60{ }^{\circ} \mathrm{C}$ and $6000 \mathrm{r} / \mathrm{min}$ with a TX-500C spinning drop interfacial tensiometer (Bowing Industry Corporation). The contact angles were measured with a JC2000D2 contact angle measurement (Zhongchen Digital Technic Apparatus Corporation). The dynamic interface modulus and interfacial tension of active nanofluids were measured with a interfacial rheometer (TECLIS Interface Technology Co., Ltd). The scanning electron microscopy (SEM) images of core slices were obtained with an S-4800 field emission scanning electron microscope (Hitachi, Ltd).

\subsection{Preparation of active nanofluids}

The silica nanoparticles were modified following the previous study (Dai et al. 2017). The active nanofluid was prepared as follows: the modified silica nanoparticles $(0.2 \mathrm{~g})$ and BSSB-12 $(0.2 \mathrm{~g})$ and distilled water $(199.6 \mathrm{~g})$ were added into a beaker. $\mathrm{NaOH}$ solution $(0.1 \mathrm{~mol} / \mathrm{L})$ was used to adjust the $\mathrm{pH}$ of the nanofluids. The nanofluids were stirred with a magnetic stirrer for $0.5 \mathrm{~h}$ and then put in an ultrasonicator for $2 \mathrm{~h}$ until the dispersion was clear and transparent. Figure 2 shows the preparation process of active nanofluids. The parameters of ultra-low permeability cores are shown in Table 1. 


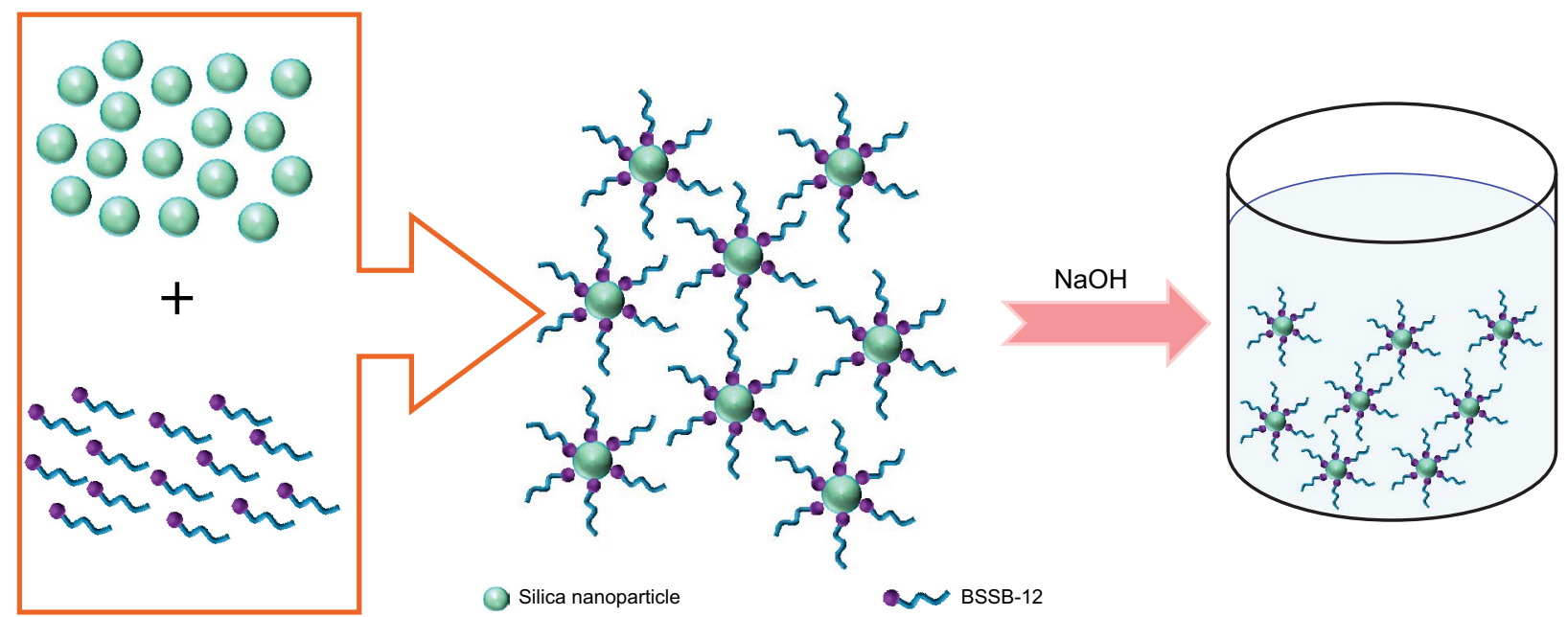

Fig. 2 The preparation process of active nanofluids

Table 1 The parameters of cores

\begin{tabular}{lllll}
\hline Number & Length, mm & Diameter, mm & Porosity, \% & $\begin{array}{l}\text { Perme- } \\
\text { ability, } \\
\mathrm{mD}\end{array}$ \\
\hline 1 & 33.24 & 25.16 & 14.55 & 0.25 \\
2 & 32.51 & 25.15 & 13.32 & 0.26 \\
3 & 33.22 & 25.07 & 14.42 & 0.23 \\
\hline
\end{tabular}

\subsection{Spontaneous imbibition tests}

The cores with a diameter of $2.5 \mathrm{~cm}$ were cut into columns with a length of $3 \mathrm{~cm}$. After dried in a vacuum oven at $110{ }^{\circ} \mathrm{C}$ for $24 \mathrm{~h}$, the cores were taken out and weighted after cooling to room temperature. Then, these cores and the simulated oil were simultaneously evacuated for $12 \mathrm{~h}$. The experimental procedures for core saturation and imbibition tests were the same as the previous study (Dai et al. 2017). After aging at $90{ }^{\circ} \mathrm{C}$ for $48 \mathrm{~h}$, the weight of cores saturated with simulated oil was recorded. The cores were immersed in $3 \mathrm{wt} \% \mathrm{NaCl}$ solution, $0.1 \mathrm{wt} \%$ BSSB-12 solution, and $0.1 \mathrm{wt} \%$ active nanofluids, respectively. The imbibition devices were placed in a constant-temperature bath at $60{ }^{\circ} \mathrm{C}$, and the volume of oil separated from cores was recorded at regular intervals.

\subsection{The broken-up behavior of oil droplets}

A microfluidic device with 3-D pore throat structure was used to simulate the pore throats in the formation, and the diagram of the microfluidic device is shown in Fig. 3.

$0.1 \mathrm{wt} \%$ BSSB-12 solution and $0.1 \mathrm{wt} \%$ active silica nanofluids were used as continuous phase and $n$-hexane was as dispersed phase. At first, the microfluidic device was placed under an inverted microscope (Leica DMi8 C). Then, the continuous phase was injected at a flow rate of $0.1 \mathrm{~mL} / \mathrm{min}$, and the dispersed phase was injected at a flow rate of $0.005 \mathrm{~mL} / \mathrm{min}$. The structure of "cross" convergence is used to generate oil droplets. The broken-up behavior of oil droplets was recorded with a Photron Fastcam SA-Z high-speed camera. Finally, the average size of oil droplets in the process of broken-up was calculated.

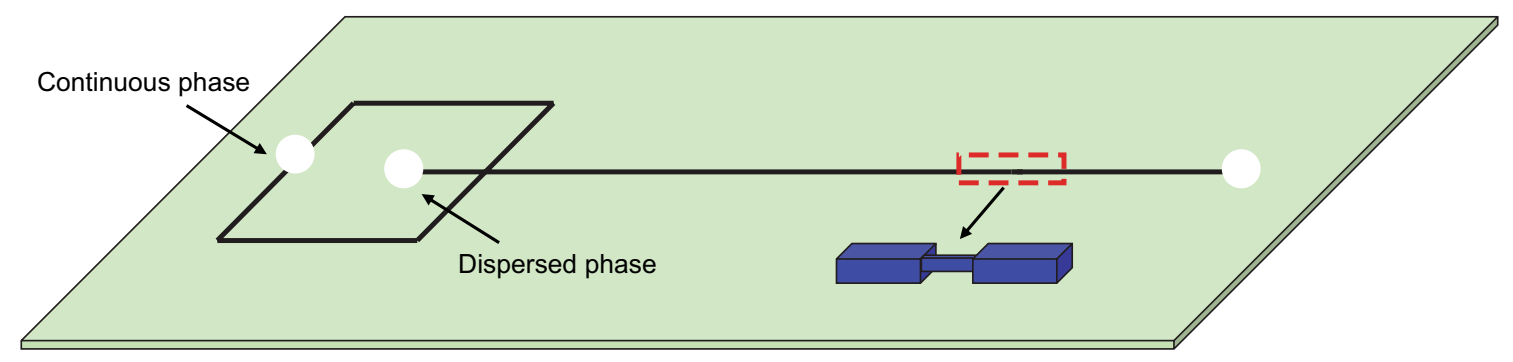

Fig. 3 Schematic diagram of the microfluidic device 


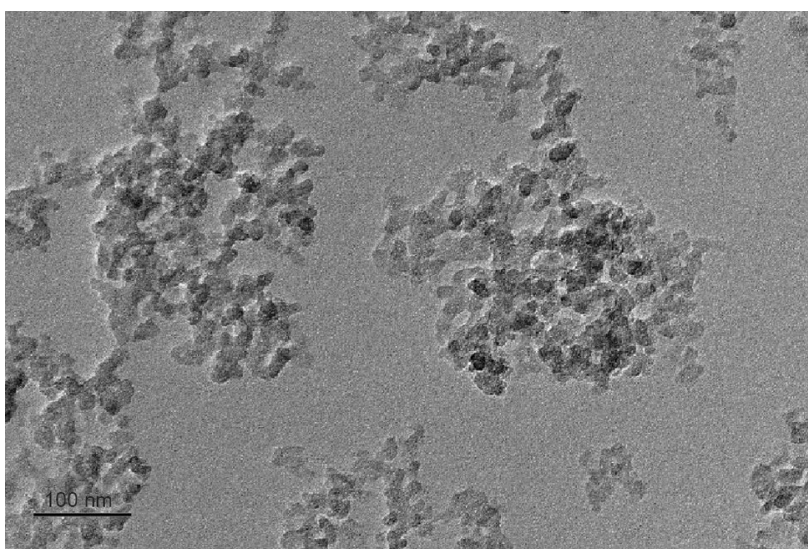

Fig. 4 TEM image of active nanofluids

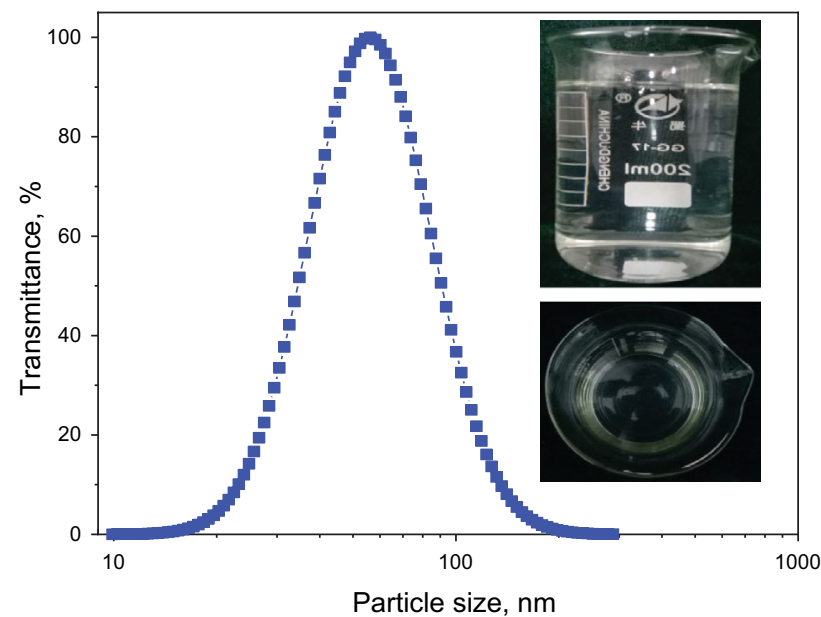

Fig. 5 The particle size distribution of active nanofluids

\section{Results and discussion}

\subsection{Characterization of active nanofluids}

The TEM image of active nanoparticles is shown in Fig. 4. The active nanoparticles were approximately spherical. The particle size of the modified silica nanoparticles was about $30 \mathrm{~nm}$. As shown in Fig. 5, the particle size distribution of active nanofluids was $10-110 \mathrm{~nm}$ and the average hydraulic radius was $58.59 \mathrm{~nm}$. The zeta potential of active nanofluids was $-48.39 \mathrm{mV}$, indicating the excellent stability. Active nanoparticles are not easy to aggregate and can be stable for a long time.

\subsection{Oil-water interfacial tension}

To investigate the effect of silica nanoparticles and BSSB12 on interfacial tensions, the interfacial tensions between the simulated oil and active nanofluids of different silica nanoparticle and BSSB-12 concentrations were measured. The results are shown in Fig. 6a. When the concentration of active nanoparticles was $0.1 \mathrm{wt} \%$, the interfacial tensions between the simulated oil and active nanofluids decreased with the increase in the concentration of BSSB-12. When the concentration of BSSB-12 was $0.1 \mathrm{wt} \%$, the interfacial tensions rarely changed with the increase in the concentration of silica nanoparticles. The minimum interfacial tension was $6.7 \mathrm{mN} / \mathrm{m}$ in the case of $0.1 \mathrm{wt} \%$ silica nanoparticles and $0.1 \mathrm{wt} \%$ BSSB-12. Based on the influence of different concentrations of silica nanoparticles and BSSB-12 on the oil-water interfacial tensions, it can be concluded that nanofluids can reduce interfacial tensions mainly through surfactant BSSB-12, and silica nanoparticles cannot greatly reduce the interfacial tension between the simulated oil and nanofluids.

The effect of active nanofluids on reducing interfacial tension can be explained by Fig. 6b. When the concentration of BSSB-12 is low, pure silica nanoparticles and silica nanoparticles coated with BSSB-12 coexist in active nanofluids. There exists a competitive adsorption of BSSB-12 between the surface of nanoparticles and the oil/water interface, which makes less BSSB-12 adsorption on the oil/water interface. Thus, the effect of reducing interfacial tension is poor. When the concentration of BSSB-12 is high, there are sufficient silica nanoparticles coated with BSSB-12. The adsorption amount on the surface of an oil droplet is enough to reduce the interfacial tension greatly. Therefore, the active nanofluids with a high concentration of BSSB-12 have a stronger ability to reduce the interfacial tension than the nanofluids with a low concentration of BSSB-12.

\subsection{Wettability alteration}

To investigate the effect of silica nanoparticles and BSSB12 on solid-liquid interface, the equilibrium contact angles between the simulated oil and active nanofluids were measured. The paraffin-coated oil-wet glass slices were aging in active nanofluids, and the final stable oil/water/solid threephase contact angles were recorded as the equilibrium contact angles. The equilibrium contact angles of silica nanoparticles and BSSB-12 with different concentrations are shown in Fig. 7a. When the concentration of active nanoparticles was $0.1 \mathrm{wt} \%$, the equilibrium contact angles increased with the increase in the concentration of BSSB-12 and the variation in wettability was $47^{\circ}$. When the concentration of BSSB-12 was $0.1 \mathrm{wt} \%$, the equilibrium contact angles increased with the increase in the concentration of active nanoparticles and the variation in wettability was $75^{\circ}$. The pure active nanoparticles or BSSB-12 cannot achieve much stronger ability to alter wettability than $0.1 \mathrm{wt} \%$ active nanofluids. The ability to alter wettability was achieved by the 
synergistic action of active nanoparticles and BSSB-12, in which the active nanoparticles played a stronger role than BSSB-12 at this point.

The effect of active nanofluids on altering wettability can be revealed by Fig. $7 b$. When the concentration of active nanoparticles was low and the BSSB-12 concentration was high, BSSB-12 formed a double-layer adsorption on the surface of oil droplets. It was difficult for active nanoparticles to approach the oil/water/solid three-phase contacting area, and the alteration of wettability mainly depended on the action of BSSB-12. This resulted in the poor effect of altering wettability. The wettability alteration caused by high concentration of active nanoparticles is consistent with the mechanism of structural disjoining pressure proposed by

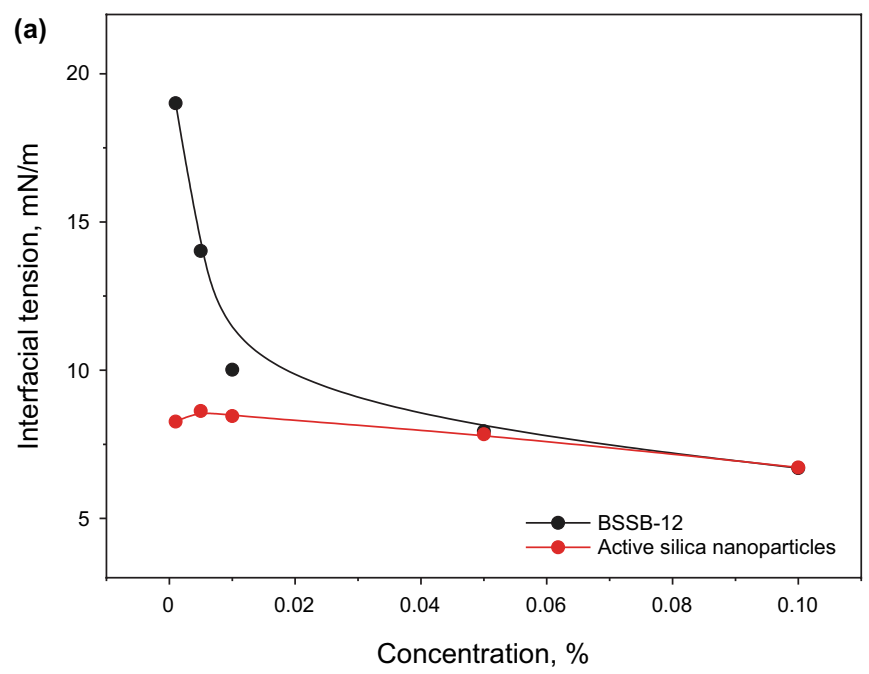

(b)

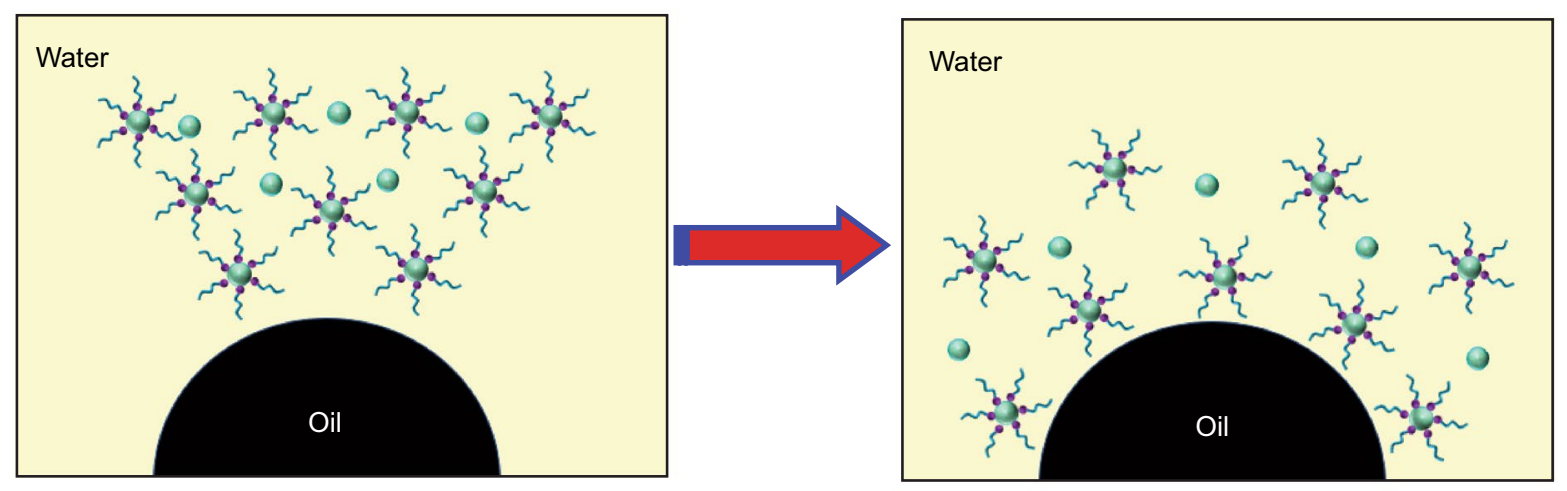

Low concentration of BSSB-12

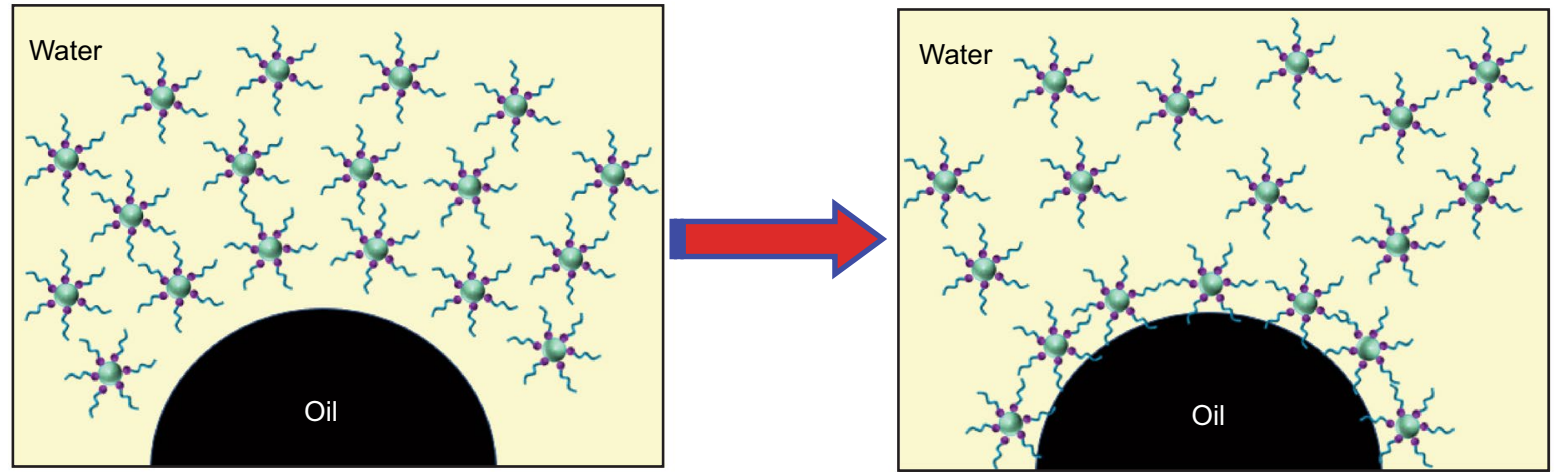

High concentration of BSSB-12

Fig. 6 The interfacial tension of different concentrations of active silica nanoparticles (the concentration of BSSB-12 was 0.1 wt\%) and BSSB12 (the concentration of silica nanoparticles was $0.1 \mathrm{wt} \%$ ) (a) and adsorption diagram of active nanofluids on simulated oil and water phases (b) 
Wasan and Nikolov (2003), Wasan et al. (2011), Kondiparty et al. (2012), and Liu et al. (2012). When sufficient nanoparticles were present, the Brownian motion of nanoparticles caused the structural disjoining pressure in the oil/water/ solid three-phase contact area and the wettability was altered to strongly water-wet. Hence, the active silica nanoparticles have a stronger ability to alter wettability than BSSB-12.

\subsection{Spontaneous imbibition}

The oil dischargement effect of $3 \mathrm{wt} \% \mathrm{NaCl}$ solution, $0.1 \mathrm{wt} \%$ BSSB-12 solution and $0.1 \mathrm{wt} \%$ active nanofluids was investigated by static spontaneous imbibition tests. The oil recovery versus time during spontaneous imbibition is shown in Fig. 8. In the initial 3 days, the oil recovery of three liquids increased rapidly with time and the active nanofluids performed the highest oil dischargement effect among the three liquids. After 4 days, the oil recovery of the active nanofluids increased continuously, while that of $3 \mathrm{wt} \% \mathrm{NaCl}$ solution and BSSB-12 solution did not change much. The final oil recovery of the active nanofluids was $26.5 \%$; the oil recovery of BSSB-12 solution and $3 \mathrm{wt} \% \mathrm{NaCl}$ solution was $17 \%$ and $6 \%$, respectively. According to the evaluation experiment of oil dischargement during spontaneous imbibition, the oil recovery of active nanofluids is higher than that of pure surfactant solution and brine, which can be ascribed to the synergistic effect of active silica nanoparticles and BSSB-12.

\subsection{The mechanism of active nanofluids during spontaneous imbibition}

\subsubsection{Oil detachment from solid surface}

The surface morphologies of ultra-low permeability core surface before and after adsorption of $0.1 \mathrm{wt} \%$ active nanofluids were observed with an S-4800 field emission scanning electron microscope (Hitachi, Ltd.), as shown in Fig. 9. As shown in Fig. 9a, the cross section of the ultra-low permeability core was rough at 20,000 times magnification. Figure $9 \mathrm{~b}$ shows the cross section after the adsorption of active nanofluids at the same time magnification. The nanoparticle adsorption layer has been formed on the cross section after soaked by nanofluids. The nanoparticles were nearly spherical, and their particle sizes were about $50 \mathrm{~nm}$, in agreement well with the TEM results. The SEM results showed that active nanofluids could enter the pore throats of the ultralow permeability core and formed effective adsorption in the pores, which provided the potential condition for nanofluids altering the surface property of pores.

To further investigate oil detachment effect of active nanofluids from the solid surface, the dynamic contact angles between $3 \mathrm{wt} \% \mathrm{NaCl}$ solution, $0.1 \mathrm{wt} \%$ BSSB-12 solution, $0.1 \mathrm{wt} \%$ active nanofluids, and simulated oil were studied. The dynamic contact angles of three solutions are shown in Fig. 10. In the initial state, all the contact angles in the three solutions were less than $90^{\circ}$ due to the oil-wet treatment of the surface of glass slices. The contact angles were invariably less than $90^{\circ}$ in $3 \mathrm{wt} \% \mathrm{NaCl}$ solution and $0.1 \mathrm{wt} \%$ BSSB-12 solution, reflecting poor ability to alter wettability. The change of contact angles in active nanofluids was significantly faster than that in the pure surfactant solution and brine. In active nanofluids, the contact angle reached the equilibrium state after $10 \mathrm{~h}$, and the final contact angle was $145^{\circ}$. The nanofluids altered the wettability of the glass slice surface from oil-wet to water-wet. The combination of the surfactant BSSB-12 and silica nanoparticles significantly improved the ability of detaching oil droplets from the solid surface.

\subsubsection{Oil transportation through pore throats}

The dynamic interfacial moduli between the simulated oil and different fluids are shown in Fig. 11a. The interfacial moduli between the simulated oil and active nanofluids increased with time, and the stable moduli were $6 \mathrm{mN} / \mathrm{m}$ after $2500 \mathrm{~s}$. The interfacial moduli of brine and the BSSB12 solution were unchanged with time, and the values of interfacial moduli were $1.2 \mathrm{mN} / \mathrm{m}$ and $0.6 \mathrm{mN} / \mathrm{m}$, respectively. Compared with brine and the pure surfactant solution, the interfacial moduli between active silica nanofluids and the simulated oil clearly increased. The results showed that a stronger interfacial film was formed due to the adsorption of active silica nanoparticles and BSSB-12 at the oil-water interface. Meanwhile, the interfacial tensions decreased with time (Fig. 11b). The interfacial tension between the simulated oil and the active nanofluids decreased from $7 \mathrm{mN} / \mathrm{m}$ to $3.5 \mathrm{mN} / \mathrm{m}$. The active nanofluids can reduce the interfacial tensions due to the strong adsorption of active silica nanoparticles at the oil-water interface to transport the oil droplets. Figure 12 shows the average size of broken-up oil droplets in the BSSB-12 solution and active silica nanofluids. The average size of oil droplets decreased with time, and the oil droplets were broken up completely after $2 \mathrm{~s}$. The size of broken-up oil droplets in the BSSB-12 solution was larger than that in active silica nanofluids. The average size of broken-up oil droplets in active silica nanofluids after 2 $\mathrm{s}$ was $17.96 \mu \mathrm{m}$, and it was easier to transport oil droplets with the help of active silica nanoparticles.

The transportation of oil in core pores and throats is mainly affected by capillary force $\left(P_{\mathrm{c}}=2 \sigma \frac{\cos \theta}{r}\right)$ and additional resistance of Jamin effect $\left(P=2 \sigma\left(1 / R_{1}-1 / R_{2}\right)\right)$. For oil-wet rocks, the capillary force is the resistance for EOR during spontaneous imbibition and the reduction in the interfacial tension will reduce the resistance to 


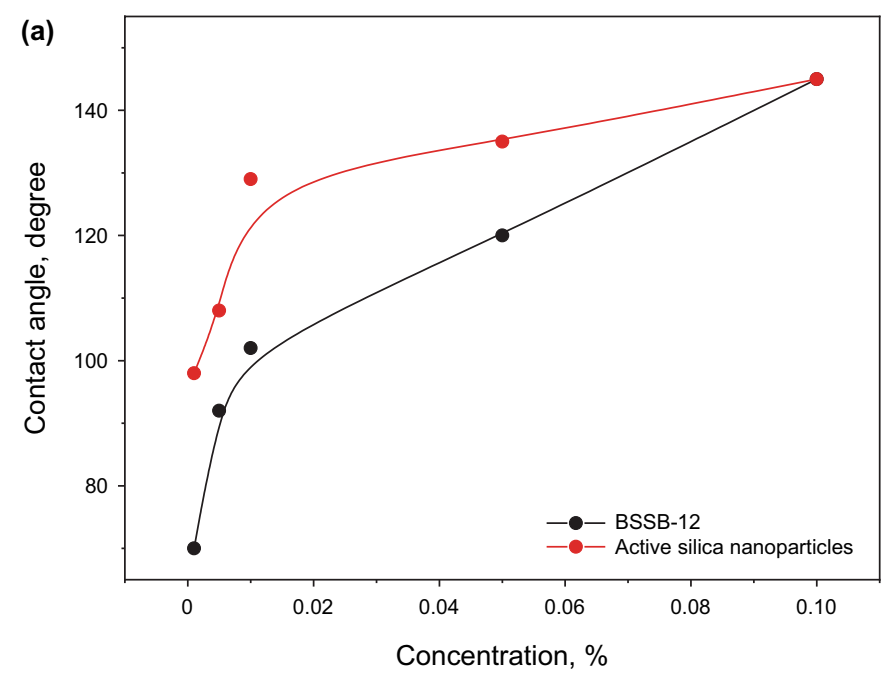

(b)

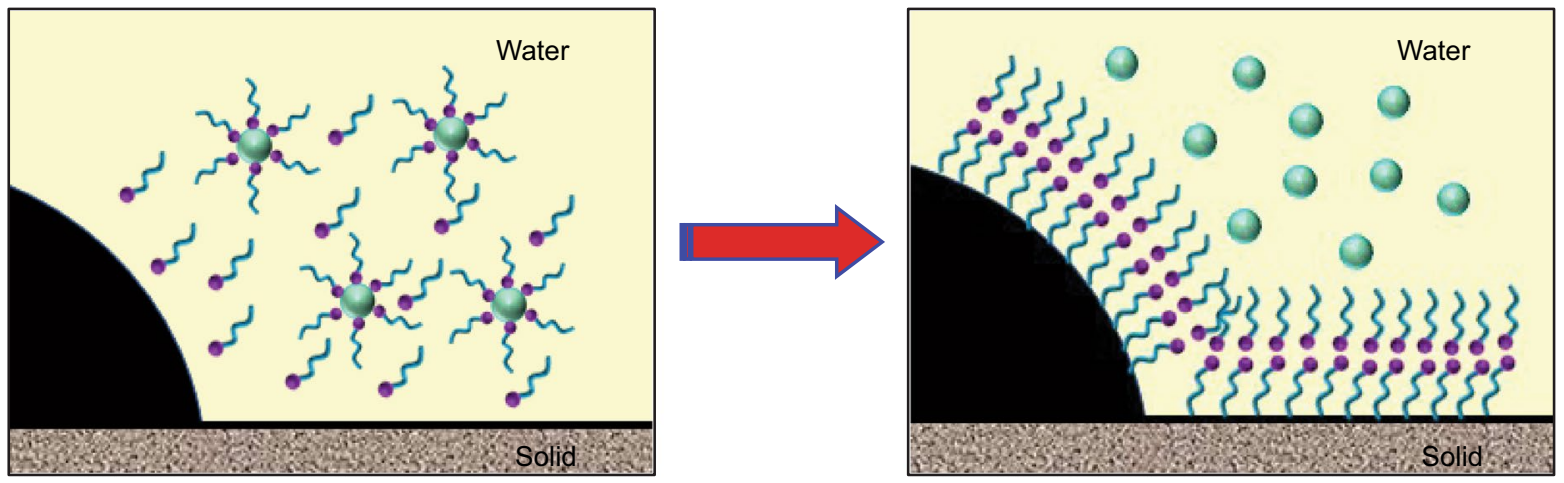

Low concentration of active silica nanoparticles
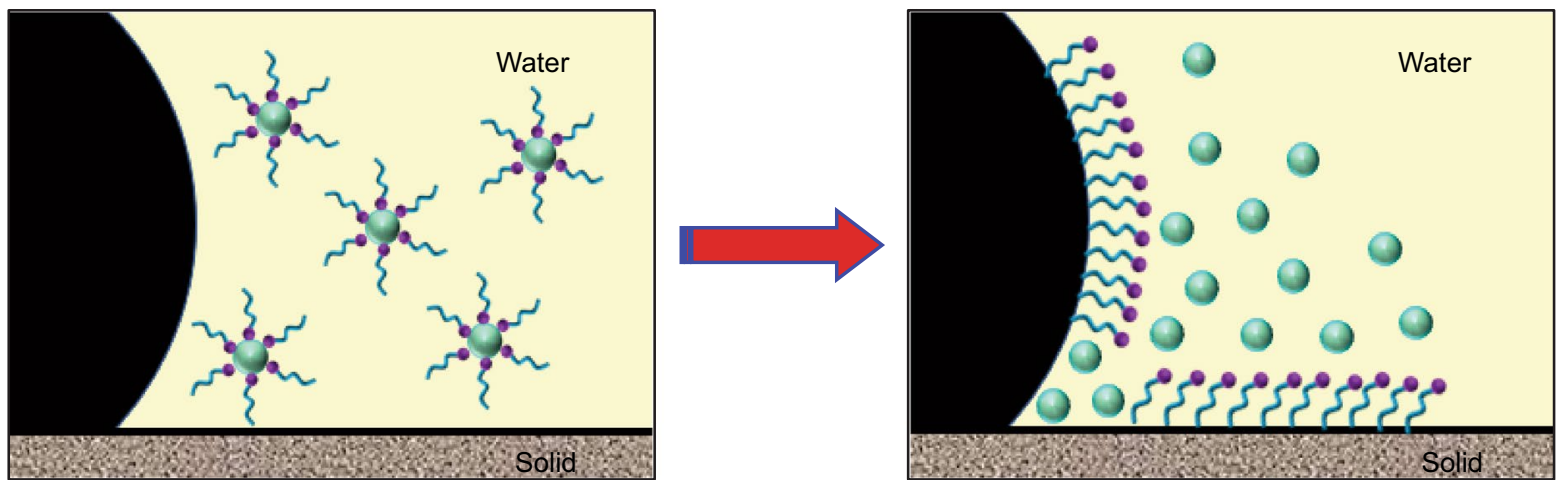

High concentration of active silica nanoparticles

Fig. 7 The equilibrium contact angles of different concentrations of active silica nanoparticles (the concentration of BSSB-12 was 0.1 wt $\%$ ) and BSSB-12 (the concentration of silica nanoparticles was $0.1 \mathrm{wt} \%$ ) (a) and adsorption diagram of active nanofluids on the oil/water/solid threephase contacting area (b)

transporting oil droplets in core pores. At the same time, when the oil droplets pass through the pore throats, a resistance effect will be produced due to the deformation of oil droplets-Jamin effect. The reduction in oil-water interfacial tension resulted in a decrease in resistance caused by the Jamin effect. The active silica nanofluids make the size of oil droplets smaller because the oil droplets are emulsified and broken-up, so the oil droplets are more likely to pass through the pore throats. Consequently, the oil droplets can pass through the small pore holes and throats with less resistance. 


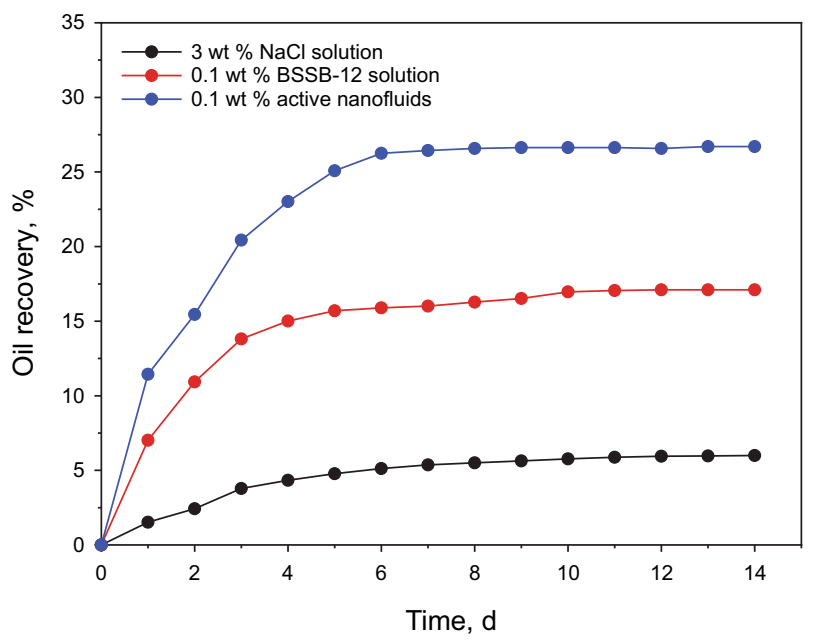

Fig. 8 The oil recovery of $3 \mathrm{wt} \% \mathrm{NaCl}$ solution, $0.1 \mathrm{wt} \%$ BSSB-12 solution, and $0.1 \mathrm{wt} \%$ active nanofluids

There are numerous studies showing that when the pore wall is hydrophilic, it is favorable for spontaneous imbibition. According to the experimental results of contact angles, the active nanofluids can change the wettability of solid surface from oil-wet to water-wet, thus changing the capillary force from resistance to motivation and enhancing oil recovery. In the process of detaching an oil drop, the adhesion work $(W=\sigma(1+\cos \theta))$ decreased through reducing the interfacial tension and altering the wettability. The mechanism figure of spontaneous imbibition is

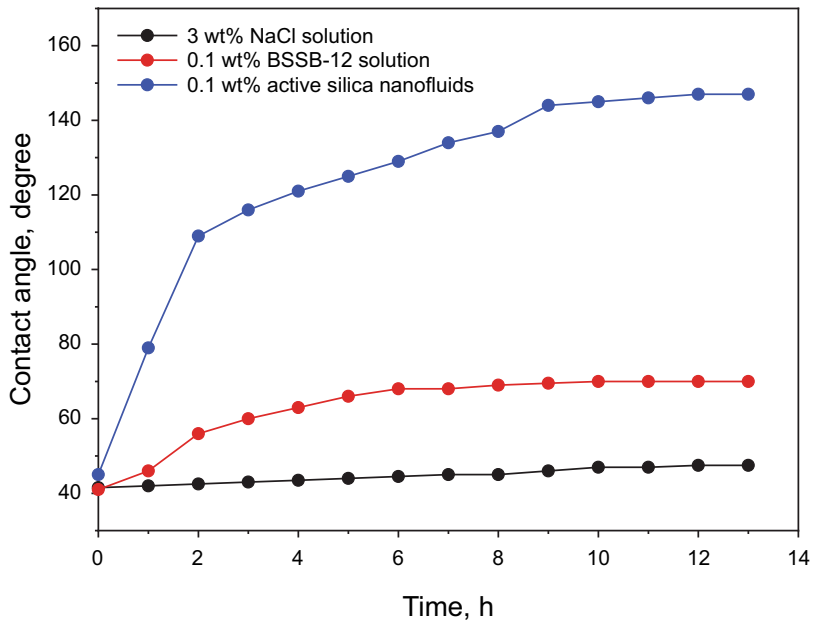

Fig. 10 The dynamic contact angles in $3 \mathrm{wt} \% \mathrm{NaCl}$ solution, $0.1 \mathrm{wt} \%$ BSSB-12 solution, $0.1 \mathrm{wt} \%$ active nanofluids

shown in Fig. 13. The BSSB-12 solution has less effect on changing wettability, so the oil recovery during spontaneous imbibition is worse than the active nanofluids. The active nanofluids can change the wettability to waterwet due to the structural disjoining pressure between the simulated oil and the pore wall generated by active silica nanoparticles. The oil displacement efficiency of ultra-low permeability cores is obviously improved by the synergistic effect of active silica nanoparticles and BSSB-12.
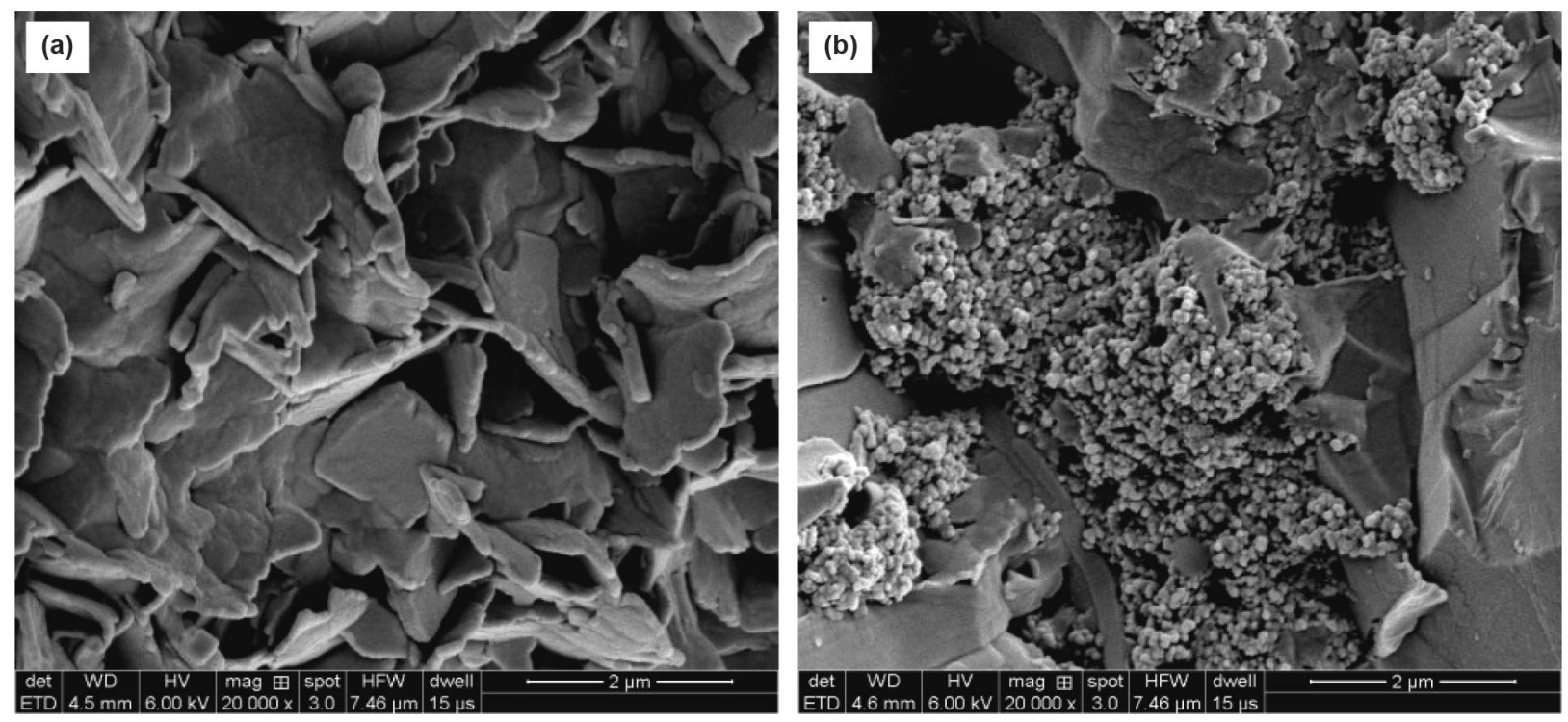

Fig. 9 The SEM images of core samples before (a) and after (b) adsorption of $0.1 \mathrm{wt} \%$ active nanofluids 

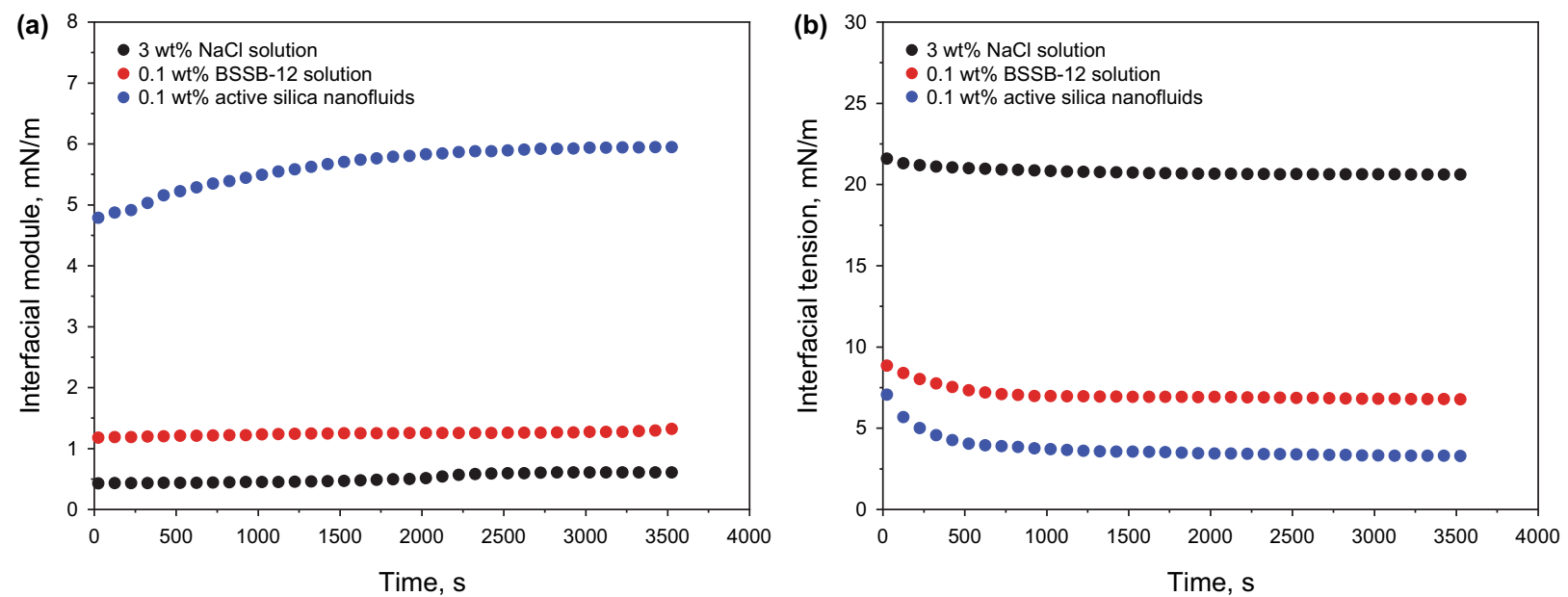

Fig. 11 The dynamic interfacial moduli (a) and interfacial tensions (b) of $3 \mathrm{wt} \% \mathrm{NaCl}$ solution, $0.1 \mathrm{wt} \%$ BSSB-12 solution, $0.1 \mathrm{wt} \%$ active nanofluids

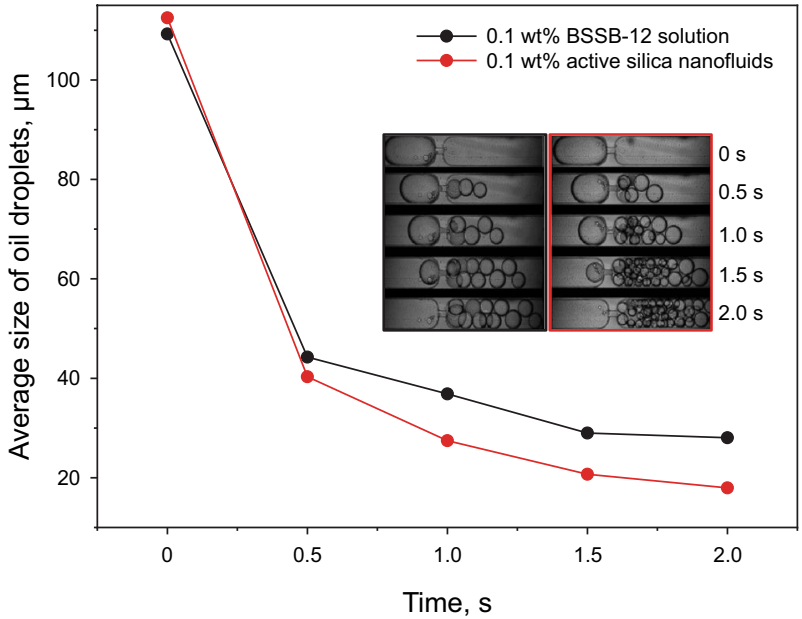

Fig. 12 The average size of broken-up oil droplets in the BSSB-12 solution and active silica nanofluids

\section{Conclusions}

1. The active nanofluids have good dispersion stability and excellent oil dischargement effect after surfactant BSSB12 adsorbed onto the surface of active silica nanoparticles.

2. BSSB-12 and active nanoparticles had their respective advantages in regulating liquid-liquid interface and solid-liquid interface to reduce interfacial tension and alter wettability.

3. When applied to EOR, the spontaneous imbibition recovery of active nanofluids could reach $26.5 \%$.

4. The mechanism for EOR was presented by the process of detaching oil droplets with the help of active nanofluids.
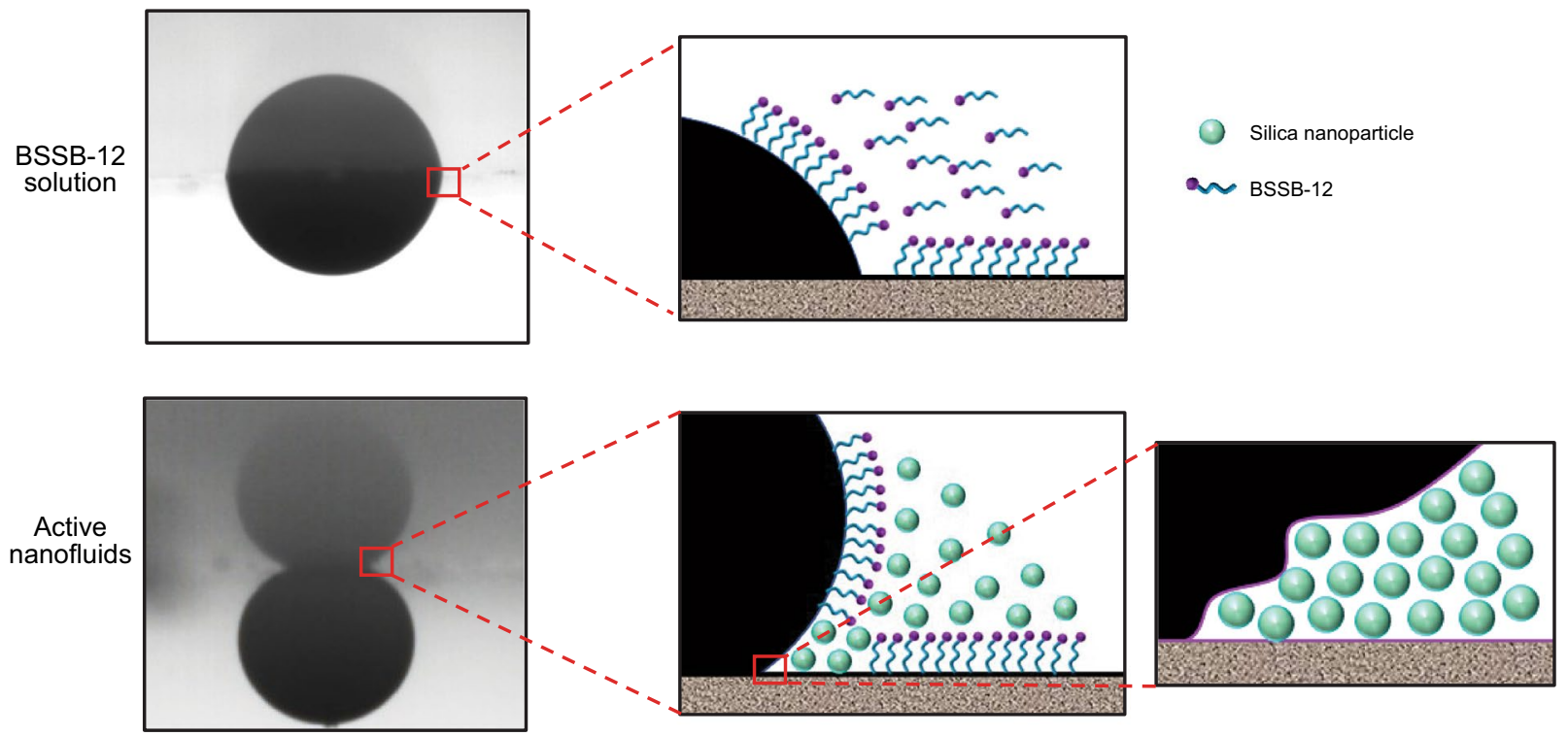

Fig. 13 The mechanism image of spontaneous imbibition 
Acknowledgements This work was financially supported by National Natural Science Foundation of China (52074333, 51874337); Taishan Scholar Foundation of Shandong Province (tspd20161004); and Fundamental Research Funds for the Central Universities (19CX07001A).

\section{Compliance with ethical standards}

Conflict of interest The authors declare that they have no known competing financial interests or personal relationships that could have appeared to influence the work reported in this paper.

Open Access This article is licensed under a Creative Commons Attribution 4.0 International License, which permits use, sharing, adaptation, distribution and reproduction in any medium or format, as long as you give appropriate credit to the original author(s) and the source, provide a link to the Creative Commons licence, and indicate if changes were made. The images or other third party material in this article are included in the article's Creative Commons licence, unless indicated otherwise in a credit line to the material. If material is not included in the article's Creative Commons licence and your intended use is not permitted by statutory regulation or exceeds the permitted use, you will need to obtain permission directly from the copyright holder. To view a copy of this licence, visit http://creativecommons.org/licenses/by/4.0/.

\section{References}

Ali A, Yahya N, Qureshi S. Interactions of ferro-nanoparticles (hematite and magnetite) with reservoir sandstone: implications for surface adsorption and interfacial tension reduction. Pet Sci. 2020;17(4):1037-55. https://doi.org/10.1007/s1218 2-019-00409-w.

Dai C, Wang S, Du M. Phase behavior of a nonaqueous ternary microemulsion containing ethylammonium nitrate, TX-100, and cyclohexane. Colloid Polym Sci. 2015a;293(5):1475-81. https ://doi.org/10.1007/s00396-015-3525-8.

Dai C, Wang S, Li Y. The first study of surface modified silica nanoparticles in pressure-decreasing application. RSC Adv. 2015b;5:61838-6184. https://doi.org/10.1039/c5ra09883a.

Dai C, Wang X, Li Y. Spontaneous imbibition investigation of selfdispersing silica nanofluids for enhanced oil recovery in lowpermeability cores. Energy Fuels. 2017;31(3):2663-8. https:// doi.org/10.1021/acs.energyfuels.6b03244.

Ehtesabi H, Ahadian M, Taghikhani V, Ghazanfari M. Enhanced heavy oil recovery in sandstone cores using $\mathrm{TiO}_{2}$ nanofluids. Energy Fuels. 2014;28(1):423-30. https://doi.org/10.1021/ef401 $338 \mathrm{c}$.

Ehtesabi H, Ahadian M, Taghikhani V. Enhanced heavy oil recovery using $\mathrm{TiO}_{2}$ nanoparticles: investigation of deposition during transport in core plug. Energy Fuels. 2015;29(1):1-8. https://doi. org/10.1021/ef5015605.

Eltoum H, Yang Y, Hou J. The effect of nanoparticles on reservoir wettability alteration: a critical review. Pet Sci. 2020;18(1):1-8. https://doi.org/10.1007/s12182-020-00496-0.

Erfani G, Hamid R, Ghazanfari MH. Application of a water based nanofluid for wettability alteration of sandstone reservoir rocks to preferentially gas wetting condition. J Mol Liq. 2017;232:351-60. https://doi.org/10.1016/j.molliq.2017.02.097.

Farad S, Afif H, Nashaat N. Hydroxyl-functionalized silicate-based nanofluids for enhanced oil recovery. Fuel. 2020;269:117462. https://doi.org/10.1016/j.fuel.2020.117462.

Foley A, Nooruddin H, Blunt M. The impact of capillary backpressure on spontaneous counter-current imbibition in porous media. Adv
Water Resour. 2017;107:405-20. https://doi.org/10.1016/j.advwa tres.2017.04.012.

Jabbari Y, Tsotsas E, Kirsch C, Kharaghani A. Determination of the moisture transport coefficient from pore network simulations of spontaneous imbibition in capillary porous media. Chem Eng Sci. 2019;207:600-10. https://doi.org/10.1016/j.ces.2019.07.002.

Jamaloei B, Asghari K, Kharrat R, Ahmadloo F. Pore-scale two-phase filtration in imbibition process through porous media at high- and low-interfacial tension flow conditions. J Pet Sci Eng. 2010;72(34):251-69. https://doi.org/10.1016/j.petrol.2010.03.026.

Kondiparty K, Nikolov A, Wasan D, Liu K. Dynamic spreading of nanofluids on solids. Part I: experimental. Langmuir. 2012;28:14618-23. https://doi.org/10.1021/la3027013.

Li R, Jiang P, Gao C. Experimental investigation of silica-based nanofluid enhanced oil recovery: the effect of wettability alteration. Energy Fuels. 2017a;31(1):188-97. https://doi.org/10.1021/acs. energyfuels.6b02001.

Li Y, Dai C, Zhou H, et al. A novel nanofluid based on fluorescent carbon nanoparticles for enhanced oil recovery. Ind Eng Chem Res. 2017b;56:12464-70. https://doi.org/10.1021/acs.iecr.7b03617.

Liu K, Kondiparty K, Nikolov A, Wasan D. Dynamic spreading of nanofluids on solids. Part II: modeling. Langmuir. 2012;28:16274-84. https://doi.org/10.1021/la302702g.

Meng Q, Liu H, Wang J. Entrapment of the non-wetting phase during co-current spontaneous imbibition. Energy Fuels. 2015;29(2):686-94. https://doi.org/10.1021/ef5025164.

Mirchi V, Saraji S, Akbarabadi M, et al. A systematic study on the impact of surfactant chain length on dynamic interfacial properties in porous media: implications for enhanced oil recovery. Ind Eng Chem Res. 2017;56(46):13677-95. https://doi.org/10.1021/ acs.iecr.7b02623.

Nowrouzi I, Manshad A, Mohammadi A. Effects of concentration and size of $\mathrm{TiO}_{2}$ nano-particles on the performance of smart water in wettability alteration and oil production under spontaneous imbibition. J Pet Sci Eng. 2019;183:106357. https://doi.org/10.1016/j. petrol.2019.106357.

Nwidee L, Lebedev M, Barifcani A. Wettability alteration of oil-wet limestone using surfactant-nanoparticle formulation. J Colloid Interface Sci. 2017;504:334-45. https://doi.org/10.1016/j. jcis.2017.04.078.

Olayiwola S, Dejam M. A comprehensive review on interaction of nanoparticles with low salinity water and surfactant for enhanced oil recovery in sandstone and carbonate reservoirs. Fuel. 2019a;241:1045-57. https://doi.org/10.1016/j.fuel.2018.12.122.

Olayiwola S, Dejam M. Mathematical modelling of surface tension of nanoparticles in electrolyte solutions. Chem Eng Sci. 2019b;197:345-56. https://doi.org/10.1016/j.ces.2018.11.047.

Olayiwola S, Dejam M. Experimental study on the viscosity behavior of silica nanofluids with different ions of electrolytes. Ind Eng Chem Res. 2020a;59(8):3575-83. https://doi.org/10.1021/acs. iecr.9b06275.

Olayiwola S, Dejam M. Interfacial energy for solutions of nanoparticles, surfactants, and electrolytes. Am Inst Chem Eng J. 2020b;66(4):e16891. https://doi.org/10.1002/aic.16891.

Peng X, Wang Y, Diao Y. Experimental investigation on the operation parameters of carbon dioxide huff-n-puff process in ultra-low permeability oil reservoirs. J Pet Sci Eng. 2018;174:903-12. https:// doi.org/10.1016/j.petrol.2018.11.073.

Qiao J, Zeng J, Feng X, et al. Characteristics of nano-micro pore networks and petroleum microscopic occurrence state in ultra-low permeability (tight) sandstone reservoir. J Nanosci Nanotechnol. 2017;17(9):6039-50. https://doi.org/10.1166/jnn.2017.14467.

Qu G, Meng Y, Shen A, et al. Experimental study of the feasibility of air flooding in an ultra-low permeability reservoir. Energies. 2016;9(10):783. https://doi.org/10.3390/en9100783. 
Saputra I, Park K, Zhang F, et al. Surfactant-assisted spontaneous imbibition to improve oil recovery on the Eagle Ford and Wolfcamp shale oil reservoir: laboratory to Field Analysis. Energy Fuels. 2016;33(8):6904-20. https://doi.org/10.1021/acs.energ yfuels.9b00183.

Standnes D. Analysis of oil recovery rates for spontaneous imbibition of aqueous surfactant solutions into preferential oil-wet carbonates by estimation of capillary diffusivity coefficients. Colloid Surf A. 2004;251(1-3):93-101. https://doi.org/10.1016/j.colsu rfa.2004.09.013.

Wang T, Zhang Y, Li L. Experimental study on pressure-decreasing performance and mechanism of nanoparticles in low permeability reservoir. J Pet Sci Eng. 2018;166:693-703. https://doi. org/10.1016/j.petrol.2018.03.070.

Wang X, Yang S, Wang Y. Improved permeability prediction based on the feature engineering of petrophysics and fuzzy logic analysis in low porosity-permeability reservoir. J Pet Explor Prod Technol. 2019;9(2):869-87. https://doi.org/10.1007/s13202-018-0556-y.

Wasan D, Nikolov A. Spreading of nanofluids on solids. Nature. 2003;423(6936):156-9. https://doi.org/10.1038/nature01591.

Wasan D, Nikolov A, Kondiparty K. The wetting and spreading of nanofluids on solids: role of the structural disjoining pressure. Curr Opin Colloid Interface Sci. 2011;16(4):344-9. https://doi. org/10.1016/j.cocis.2011.02.001.

Wu H, Gao K, Lu Y. Silica-based amphiphilic Janus nanofluid with improved interfacial properties for enhanced oil recovery. Colloid Surf A. 2020;586:124162. https://doi.org/10.1016/j.colsu rfa.2019.124162.
Xie X, Weiss W, Tong Z. Improved oil recovery from carbonate reservoirs by chemical stimulation. SPE J. 2005;10(3):276-85. https ://doi.org/10.2118/89424-PA.

Xu Z, Li S, Li B, et al. A review of development methods and EOR technologies for carbonate reservoirs. Pet Sci. 2020;17:990-1013. https://doi.org/10.1007/s12182-020-00467-5.

Zhang Y, Gao M, You Q. Smart mobility control agent for enhanced oil recovery during $\mathrm{CO}_{2}$ flooding in ultra-low permeability reservoirs. Fuel. 2019;241:442-50. https://doi.org/10.1016/j. fuel.2018.12.069.

Zhao F, Zhang L, Hou J, Cao S. Profile improvement during $\mathrm{CO}_{2}$ flooding in ultra-low permeability reservoirs. Pet Sci. 2014;11(2):27986. https://doi.org/10.1007/s12182-014-0341-6.

Zhao M, Lv W, Li Y, et al. Study on the synergy between silica nanoparticles and surfactants for enhanced oil recovery during spontaneous imbibition. J Mol Liq. 2018;261:373-8. https://doi. org/10.1016/j.molliq.2018.04.034.

Zhao M, Song X, Zhou D, et al. Study on the reducing injection pressure regulation of hydrophobic carbon nanoparticles. Langmuir. 2020;36:3989-96. https://doi.org/10.1021/acs.langmuir.0c00115.

Zhong X, Li C, Pu H. Increased nonionic surfactant efficiency in oil recovery by integrating with hydrophilic silica nanoparticle. Energy Fuels. 2019;33:8522-9. https://doi.org/10.1021/acs.energ yfuels.9b02245.

Zhou H, Zhang Q, Dai C, et al. Experimental investigation of spontaneous imbibition process of nanofluid in ultralow permeable reservoir with nuclear magnetic resonance. Chem Eng Sci. 2019;201:212-21. https://doi.org/10.1016/j.ces.2019.02.036. 